\title{
14
}

\section{(Dif)fusions: Modern Fiction and Communal Form}

\author{
We are \\ of one mind, tuning \\ our instruments to ourselves, by our triple light. \\ -Olga Broumas, "Triple Muse" \\ Where no community exists, "we" may seem to presume \\ too much. \\ - Marie Ponsot and Rosemary Deen, \\ Beat Not the Poor Desk
}

$\mathrm{B}_{\mathrm{y}}$ recognizing multiple perspectives both formally and philosophically, modernism (re)turns narrative voice from the hegemonic individualism that I have been associating with the nineteenth century to narrative structures in which two or more characters may constitute a narrating community without suppressing their personal identities. This formal possibility coincides with a period in women's writing in which, according to Rachel Blau DuPlessis, "individual heroes" and "sealed couples" are of ten replaced by "collective" protagonists and "groups which have a sense of purpose and identity, and whose growth occurs in mutual collaboration." The fictions I will be discussing in this chapter reflect the intersection of this new communality of representation with conventions that also allow communality of narrative voice.

1. Rachel DuPlessis, Writing beyond the Ending: Narrative Strategies of Twentieth-Century Women Writers (Bloomington: Indiana University Press, 1985), 179. 
As I noted in my discussion of Herland, representations of female community or what DuPlessis calls "collective" protagonists do not necessarily entail communal voice. Little Women (1868-69) constructs a domestic, female community of four sisters, but Meg, Jo, Beth, and Amy are not narrators of their own histories. Bound to the authorial conventions of realist fiction, Little Women can create the sisters as a verbal community only through copious direct speech, as black community is constituted in Contending Forces and Iola Leroy. Conversely, as I have also noted, many novels use multiple voices (and protagonists) without constructing the kind of community DuPlessis describes; the narrating characters do not share "a sense of purpose and identity" and their growth does not occur "in mutual collaboration"; on the contrary, in a novel such as Les Liaisons dangereuses, it is disruption and destruction that multiplicity represents.

From among various forms of novelistic multiplicity, then, I am distinguishing the convergence of representation and narration that occurs when a collective or group protagonist is represented through formal strategies that allow the plurality itself to speak. I want to explore in this chapter two different techniques, with different ideological implications, for giving collective protagonists a communal voice: simultaneous, first-person-plural narration in a literal "we" that allows voices to speak in unison, and sequential narration in which each voice speaks in turn so that the "we" is produced from a series of collaborating "I's." Apart from the not-insignificant challenge that both forms pose to individualist narrative authority, both also entail deviations from narrative conventions: simultaneous communal voice challenges the convention that feelings, perceptions, and thoughts are necessarily individual, while sequential voice threatens conventions of novelistic "coherence" and continuity. In turn, both forms of communal voice are contained and constrained by conventions of representation, not least by the institutionalized heterosexuality that I have been suggesting is at the heart of Western fictional teleology.

I have explained that in The Country of the Pointed Firs a plural voice that narrates collective perceptions transgresses Western fiction's conventionally singular notions of consciousness. While this singularity may seem to be a natural extension of the properties of spoken discourse, I want to locate it at least provisionally as the product of individualist cultures which presume consciousness to be unique and literature the "original" product of single authorship. If Western lit- 
erary cultures do not readily allow for "I's" who speak or perceive as "we," other Western discourses from science to bureaucracy to mass media certainly practice plural narration, and oral traditions in most cultures of the world acknowledge the ways in which an "I" may speak as "we" and collective consciousness be the very foundation of cultural identity.

By simultaneous voice I refer to a narrative situation in which both voice and focalization are represented as communal, so that the "we" who perceives is also the "we" who speaks. I am not aware of novels in a white male tradition written in such a voice, but I will examine some of the possibilities and limits of this form through three novels by women in the United States. The first two construct the "we" from an "I" and thus do not entirely reduce the hierarchical distinction between self and other: Sarah Orne Jewett's Deephaven (1877) creates a "we" of two women in love; Toni Morrison's The Bluest Eye (1970), a "we" of two sisters that comes to include other black adolescents and ultimately a larger community. Joan Chase's During the Reign of the Queen of Persia (1983) dispenses with the "I" entirely, constructing (as its predecessor Little Women could not) an entirely plural narrative voice that represents four female cousins, two pairs of sisters, whose growing-up years are told as if experienced through a single mind. I shall argue, however, that these exceptional novelistic constructions prove Beauvoir's rule that "women do not say 'we,' " for in all three, communal voice is restricted to the representation of childhood or young adulthood in ways that fail to challenge the novel's adherence to institutional heterosexuality.

While Deephaven's narrator is nominally individual, she narrates almost entirely from the kind of plural consciousness that occurs only momentarily in The Country of the Pointed Firs. Although once again this "we" comes formally into being during an idyllic vacation, the voice constructed in Deephaven is not produced through a geographic community; it is the voice of two women, Helen and Kate, who spend a long summer together in the house of Kate's late aunt. Helen, technically the narrator, explicitly and emphatically seeks to construct herself as a plurality: "I am not writing Kate's biography and my own, only telling you of one summer which we spent together."2 The narrator speaks much more about the couple than about either individual,

2. Sarah Orne Jewett, Deephaven (1877; reprint, Boston: Houghton Mifflin, 1895), 25. All further references will appear in the text. 
recording their thoughts, feelings, fears, desires, as those of a single consciousness: "we are neither of us nervous" (16); "a friendship which we both still treasure" (11); "the west parlor was our favorite room downstairs" (19); "It was very sad work to us-saying goodbye to our friends, and we tried to make believe" (241). The text even sets up a scene of collaborative writing in which on two "old secretaries" that were "facing each other" Helen and Kate "wrote, between us, a tragic 'journal" " and "put it in the most hidden drawer by itself, and flatter ourselves that it will be regarded with great interest some time or other" (16).

Although stories about the villagers are integrated into the novel, Kate and Helen do not require Deephaven, as the narrator of Pointed Firs requires Dunnet Landing, to establish a communal voice. This voice, like their relationship, is predicated on their not really belonging to Deephaven so that they can deepen an already-established relationship; unlike Pointed Firs, this novel begins and ends in Boston. The novel's title, then, becomes not simply the signifier of geographic community, as it does in Pointed Firs and Cranford, but in a more coded way the deep haven of an essentially lesbian société $\grave{a}$ deux. If anything, the "we" is emphasized rather than diminished in the last chapter; in long passages of dialogue, Kate and Helen reflect together upon their happiness at Deephaven, and the final pages of the book recall not the people of Deephaven but the ways in which two of them spent their time, so that what is emphasized is the "we" that is separate from the larger community and will continue apart from it.

Indeed, the book's innocuous title obscures the central drama of romantic union being inscribed in both story and voice. Just two pages into the book the narrator reports that the two women "kissed each other solemnly" (2) and defends this act with a pert injunction to the narratee: "You need not smile; we are not sentimental girls, and are both much averse to indiscriminate kissing" (2). The narrator freely admits that the pair is an object of village curiosity, and tells us how they would "lie on [the sofa] together" (21); Kate even "laughingly proposed" one evening that they "copy the Ladies of Llangollen, and remove ourselves from society and its distractions" (242). Yet these lesbian suggestions are mitigated by a discourse that renders the characters childlike. Although they are twenty-four-year-old women, "you would have thought we were two children" (3); Deephaven "might be dull... for two young ladies" but not "for two little girls who were fond of each other" (4); "Sometimes in Deephaven we were between 
six and seven years old" (35); they looked forward to the circus "with as much eagerness as if we had been little school-boys" (120); and each has a favorite children's book that she carries about with her $(248-49)$. This emphasis on childhood desexualizes the relationship and attempts to render it ideologically innocent.

The other two simultaneous communal narratives I want to discuss create their voice literally through children - or rather through adults looking back upon a shared childhood. In Toni Morrison's first novel, Claudia's personal voice frequently becomes the "we" of "my sister [Frieda] and I,"3 constructing not only shared experience but a shared point of view that presumes Claudia's ability to know Frieda's mind as one would know one's own: "There was nobitterness in our memory of him" (17); "we were full of awe and respect for Pecola" (28); "we looked hard for flaws to restore our equilibrium" $(55)$; "we were sinking under the wisdom, accuracy, and relevance of Maureen's last words" (61); "we were embarrassed for Pecola" (147); "we thought only of this overwhelming hatred for the unborn baby" (148). This repeated "we" suggests- despite explicit differences, for example, in Claudia's and Frieda's reactions to white baby dolls-a commonality of thought and even of memory, a sisterhood that experiences and perceives the world in unison.

This "we" also expands beyond the biological sisterhood to embrace a wider community. In this passage, the narrator is speaking not only for herself and Frieda, but for all black girls oppressed by white standards of beauty: "We were lesser. Nicer, brighter, but still lesser. Dolls we could destroy, but we could not destroy the honey voices of parents and aunts, the obedience in the eyes of our peers, the slippery light in the eyes of our teachers when they encountered the Maureen Peals of the world. What was the secret? What did we lack?... We felt comfortable in our skins... and could not comprehend this unworthiness" $(61-62)$. Sometimes the "we" includes adults as well: "Black people were not allowed in the park, and so it filled our dreams" (84). And as I proposed in Chapter 7, at the end of the novel the "we" becomes by implication an entire generation of northern AfricanAmericans who "were not strong, merely aggressive," "not free, merely licensed," "not good, but well behaved" (159). Obviously Morrison's message in using the communal "we" is to make clear the

3. Toni Morrison, The Bluest Eye (New York: Pocket Books, 1970), 9. All further references will appear in the text. 
degree to which the experience of an individual black female "I" is collective experience; the text sets this "we" of typical black girls against the overprivilege of Maureen Peal and the underprivilege of Pecola. Indeed, Pecola is part of the "we" only when she is living with Claudia's family; it is the absence of the sense and the reality of the "we" that finally leads after her rape to the madness born of her longing for blue eyes. Claudia and Frieda, on the other hand, survive in part because they are allowed to grow up both together and as individuals, the "I" and the "we" making each other possible.

Joan Chase's During the Reign of the Queen of Persia (1983) goes further still: it has no "I" narrator at all, but only a "we" that becomes the sole constituent of narrating-though not narrated-identity. Chase's narrator comprises four girls, "two [Uncle Dan's] own daughters, two his nieces, all of us born within two years of each other," who during the 195 os live more-or-less together, with their grandmother and various parents, uncles, and aunts, on the family farm. The narrative reflects a single group consciousness because people "treated the four of us the very same and sometimes we thought we were the same." Thus not only feelings and perceptions but direct thoughts and direct speech are attributed to this "we": "We accused her. 'How do you know a thing about it?" " (22); "Didn't she save you, we thought" (25); “ 'He loved her a lot,' we said, recalling his masking indolence" (44); "We are humiliated. He has shown again that we are his stupid, flighty, undisciplined daughters" (140); "We were aghast" (188); "We didn't know what to think" (272); "We had bad dreams, cried out at night" (196). This "we" survives even the temporary absence of any one or two of its constituents. Any of the four girlsAnne, Katie, Celia, or Jenny-might be temporarily a "third person," a character set apart from the collective voice and thereby individualized, marked in difference. Thus at one moment "Aunt Libby was still sewing and instructing us... while Celia stayed shut away in her room” (30), or “ 'You didn't call me. You left me.' Anne was screaming at us" (222). The novel is able, in other words, to take advantage of the semantic fluidity of the "we" to maintain the communal voice despite the momentary difference or even defection of an individual "I." The very continuity of the "we" allows each "she" to rejoin it for occasions of shared narrative identity, as in the powerful moment when all four

4. Joan Chase, During the Reign of the Queen of Persia (New York: Harper and Row, 1983), 5. All further references will appear in the text. 
are hoping for a miracle to save Aunt Grace, one of the mothers, from cancer: in their "yearning to believe" (194), it seems "as though her presence and our devotion to her had united us at last in a perfect oneness, we four girls thinking, feeling and moving in a dimension that felt like the exact representation of a greater mind" (196). This "exact representation of a greater mind" is indeed what this novel achieves through its unconventional and entirely communal voice.

However, Chase's "we" seems to me viable not only as technique but as representation because the four girls are a "natural" community; they share family and history and live together in a single place. I am theorizing that the "we" is predicated on a kind of unity that the heterosexual conventions of the novel permit far more readily to young girls than to grown women, whose lives are assumed to diverge and become, to recall Beauvoir, "dispersed among the males." The "we" of childhood becomes both nostalgic and utopian, as if community cannot survive as girls grow to womanhood. Even in Deephaven the women are still young, their romantic relationship represented as but an episode before the shared life splits into separate, presumably heterosexual histories; it is only "laughingly," after all, that they propose to run off together like the Ladies of Llangolen. It seems significant, therefore, that contemporary novels representing communities of adult sisters or friends do not seem to use such simultaneous communal forms. Maria Katzenbach's The Grab (1977), a novel about three sisters whose mother has just died, intersperses direct monologue with authorial narration to render some sense of each sister's feelings about her mother; authorial voice with shifting focalization is likewise the mode of Candyce Flint's novel of three sisters, Mother Love (1987). Ntozake Shange's Sassafrass, Cypress E Indigo (1982) creates three sisters as a collective protagonist, but each is given her own point of view and her own portions of text, which are organized and orchestrated by an authorial voice who uses free indirect discourse, letters, recipes, journal entries, and other private forms to render each sister's individuality.

Narrative convention may not, however, be the only reason for the paucity of simultaneous voice in the novel; there are good grounds for caution about a narrative method that cannot distinguish among the individual members of a collectivity. If the "we" is at its best the expression of a harmonious unity-in-multiplicity, of what my epigraph from Olga Broumas describes as "one mind, tuning / our instruments to ourselves," it also always risks erasing difference beneath pre- 
sumptions of similarity. ${ }^{5}$ In the warnings of Marie Ponsot and Rosemary Deen (themselves a "we"), "where no community exists, 'we' may seem to presume too much." "If "we" dissolves the Other/Self dichotomy, its danger lies in its power to reduce each Other to an explicit or-perhaps more troublingly-implicit norm. The utopian value of the "we" is counterbalanced, then, by the equally strong dystopian danger of speaking for women, or a particular group of women, "in general."

The impulse to balance these tensions of unity and diversity, commonality and difference, surely explains why feminism particularly in the 1980s produced an entire genre of anthologies based on personal (primarily but not exclusively nonfictional) narratives organized to show difference within a particular, shared aspect of identity. Women who identify themselves as members of marginalized ethnic or political communities have been especially active in writing books that represent their particular groups through the individual voices of separate but resonant experiences. These books-I have in mind such collections as The Coming Out Stories, This Bridge Called My Back: Writings by Radical Women of Color, Nice Jewish Girls: A Lesbian Anthology, With the Power of Each Breath: A Disabled Women's Anthology, You Can't Drown the Fire: Latin American Women Writing in Exile, Lionheart Gal: Life Stories of Jamaican Women, Making Waves: An Anthology of Writings by and about Asian American Women, and Charting the Journey: Writings by Black and Third World Women - carry the double imperative of constituting an unheard "we" and literally articulating that "we" into its diverse constitutive elements. Both imperatives are recognized as crucial gestures for inscribing minority identities in a dominant culture that both disperses and falsely unifies.

Some feminist novelists, especially those who are identified with a marginalized community, have likewise attempted to represent both similarity and difference by constituting a multiplicity of individual female voices that echo one another through experiences and perceptions that are also distinct. These voices are not competing for authentic versions of a narrative or offering multiple perspectives on a single story, but are offering multiple stories, each one contributing

5. I have written further about the implications of the pronoun "we" in "Who Are the 'We'? The Shifting Term of Feminist Discourse," Women's Studies Quarterly 14 (Fall-Winter 1986): 18-20.

6. Marie Ponsot and Rosemary Deen, Beat Not the Poor Desk: Writing: What to Teach, How to Teach It, and Why (Montclair, N.J.: Boynton-Cook, 1982), 137. 
to a fuller portrait of a specific community. Ntozake Shange's "choreopoem" for colored girls who have considered suicide/when the rainbow is enuf (1975) is perhaps one of the prototypes for such works: seven "ladies," distinguished only by the color of their dress, enact representations of African-American women. Many of the narratives in Shange's text evoke figures of history or myth, but the emphasis is on contemporary black women's experiences, thoughts, and feelings told in their own words. Male voices, when they speak at all, are usually unreliable voices present, as they were in Riccoboni's novels, to be criticized and ironized. Shange sees the separate poems as "a single statement" intended to "sing a black girl's song" and "let her be born."

The sequential communal narratives I wish now to examine function like Shange's "choreopoem," giving voice to a diversity of women of some shared identity without making any single experience or consciousness normative. Such communal narratives are perhaps less common in the novel than in other artistic forms because they necessarily threaten novelistic conventions of representational coherence and structural unity. As I mentioned in Chapter 5 , when novels produce what Macherey calls a "dispersal," narrative voice becomes one of the major mechanisms for containing the narrative as a unity. This may be why many novels use communal strategies only momentarily, incorporating women's voices but maintaining authorial narration as their dominant mode. For example, Mary Gordon's The Company of Women (1980) represents first the indirectly rendered thoughts and finally the direct voices of a group of women struggling to create their individual and collective identities in a community dominated by a Catholic priest, though the center of the novel is a figural narrative focused on a single character. And Morrison's Beloved yields its authorial voice at a particularly intense moment in the relationship of Sethe and her two daughters in order to create interior monologues and finally a communal blend of the three voices. Louise Erdrich's three novels, Love Medicine (1984), The Beet Queen (1986), and Tracks (1988), go further, creating (Balzacian) recurring characters who are represented through a spectrum of voices, both authorial and personal, that together might be said to constitute the voice(s) of a particular, predominantly Native American community.

The retention of authoriality characterizes some recent novels that

7. Ntozake Shange, for colored girls who have considered suicide/when the rainbow is enuf (New York: Macmillan, 1975), xx. Shange locates the inspiration for her work in Judy Grahn's "Common Woman" poems. 
are explicitly structured to represent the intersecting but by no means unified history of a female community. Gloria Naylor's The Women of Brewster Place (1982) and Pat Barker's Union Street (1983) use place rather than plot as a unifying principle for exploring the lives of poor urban women, respectively African-American and white British, as female communities. Perhaps because they transgress conventional expectations of plot, these books retain authorial voice and rely on free indirect discourse to represent each character's consciousness, constructing formal coherence by narrating diverse stories and characters in a single authorial voice.

On the other hand, the narrative structure of Amy Tan's The Joy Luck Club (1989), which Tan claims to have been inspired by Love Medicine, does construct through a series of homodiegetic narratives a sequential communal voice. A mah-jongg group becomes the device through which seven women, three Chinese immigrant mothers and four Chinese-American daughters, narrate interlaced segments of their own histories. Here too, of course, family and longtime friendship constitute unifying principles, and even then, the alternation of voices means that most of the stories are not fully developed. The fact that none of the narrator's stories is wholly constituted suggests, indeed, that the book's emphasis is the representation of a spectrum of mothers and daughters, and mother-daughter relationships, within an ethnically and geographically defined community. The orchestration of voices-each character speaks more than once, and in unsystematic order-provides precisely the design that makes the book novelistic rather than a set of stories, and the novel's final image-in which daughters of the same mother finally meet and, in their recognition of one another, recognize their dead mother-constitutes a moving representation of the text's own imperative to balance the samenesses and differences within a community: "I look at their faces and I see no trace of my mother in them. Yet they still look familiar. ... And although we don't speak, I know we all see it: Together we look like our mother. Her same eyes, her same mouth, open in surprise to see, at last, her long cherished wish." then, allows each narrator a separateness and indeed a separate authority, yet each also helps to create the portrait of an identifiable group.

All these works that I am associating with sequential narration, like

8. Amy Tan, The Joy Luck Club (New York: Putnam's, 1989), 287-88. 
the nineteenth-century novels of "singular" communal voice before them, necessarily deviate from classical fictional form. The need for more open structures than the realist novel to accommodate the narrative effects of sequential communal voice may explain why the contemporary work I have encountered that succeeds most fully in fusing a diffuse group of female voices into a self-conscious, egalitarian narrating community returns to an older form more atomized than the novel even in its modern(ist) modes. The book I have in mind is Julia Voznesenskaya's The Women's Decameron: A Novel (1985), which uses the Boccaccian framework to build a female community in which each voice is fully authorized. Ten Russian women who have just given birth, quarantined to the maternity ward with skin infections, decide to pass their ten days of confinement by telling stories; each day has a topic, and the stories usually concern private and unspeakable aspects of women's lives: sexual initiation, rape, infidelity. In contrast to the original Decameron, these women tell personal stories as well as stories about others, so that they are homodiegetic and heterodiegetic narrators in turn. Each has her own narrative style and preferences, and through the metanarrative act of creating its characters not simply as voices but as storytellers, the novel legitimates every woman's diegetic and mimetic authority.

Indeed, The Women's Decameron creates community precisely through its own narrative acts, as the ten women are transformed through their storytelling from a collection of diverse individuals to a group of narrators and finally to a loving community of considerable shared consciousness. The women start out as a quarrelsome and disparate group who have in common only gender, babies, and boredom: there are party members and political dissidents, proper wives and unmarried mothers, educated women and women of the working class. But as one of the bolder women says, "What's there to be shy about?... We're all women, aren't we? We all love with the same part of the body, don't we?" From this rudimentary commonality the women begin to know one another through their stories and to learn that they have much more in common than biological "parts." Brief transitional sections between the stories chart the development of community as the women come to know one another through the intimacy of their narratives. By the seventh day, for instance, the "ice 
finally seemed to have melted" (182), even between Valentina the "party bigwig" (3) and Galina the "dissident wife" (22). As the women tell stories that reveal themselves ever more deeply and sometimes more painfully, they also become a caring community: "the women comforted Galya herself as best they could, for she had concluded her story in tears" (188). Two women even become "characters" in another woman's history when they find a way to contact the father of her child.

This movement toward community is not only psychological but ideological, and it is the recognition of shared experience that forges the unity. While the early part of the book featured stories about "mothers-in-law" as "bitches" and nostalgic recollections of heterosexual first love, on the eighth day Galina tells about the "wisdom and goodness" of her mother-in-law (224), and the women joke that "you do occasionally get men who are genuine people" (224). They also begin to identify issues of mutual concern such as physical safety and child care, developing across other ideological differences a shared stance and even rudimentary plans for action. It is significant, however, that the text ends quite abruptly after the tenth story on the tenth day; it inscribes neither the inevitable dispersion of the community nor any continuance beyond the hospital walls.

In The Women's Decameron, a group of Soviet women, simply because they are Soviet women and allowed to tell stories of their own choosing entirely among themselves, construct by their own narrative acts a communal voice and a communal history for a communal audience of themselves. By U.S. feminist standards, the ideology of this book is less oppositional than its form might in theory permit: all the women are mothers; the stories still center primarily on heterosexual plots; lesbians get stereotyped with phrases like "butch dyke." Perhaps the very communality of such a narrative project means that certain values and norms may end up constituting their own hegemony. That is, while all narration is of course limited to and by the voices who tell it, this limitation may be obscured in communal narrative situations precisely by narrative plurality; whatever similarities emerge across differences, whatever spaces are not opened to dialogue, are bound to be reinforced. Here, indeed, is the insidious underside of the single author's power to masquerade as a self-reinforcing community. Even the most "open" form for the inscription of communal voice, then, ought not be idealized; form is only possibility, the necessary but never sufficient means for transforming both fiction and consciousness. 